\title{
Proposta de Suporte ao Padrão MPI sobre Infraestrutura de Comunicação de Baixo Nível no Nanvix
}

\author{
João Fellipe Uller ${ }^{1}$, João Vicente Souto ${ }^{1}$, Pedro Henrique Penna ${ }^{2,3}$, Márcio Castro ${ }^{1}$ \\ ${ }^{1}$ Laboratório de Pesquisa em Sistemas Distribuídos (LaPeSD) \\ Universidade Federal de Santa Catarina (UFSC) - Florianópolis, Brasil \\ ${ }^{2}$ Laboratoire d'Informatique de Grenoble (LIG) \\ Université Grenoble Alpes (UGA) - Grenoble, França \\ ${ }^{3}$ Grupo de Arquitetura de Computadores e Processamento Paralelo (CArT) \\ Pontifícia Universidade Católica de Minas Gerais (PUC Minas) - Belo Horizonte, Brasil

\begin{abstract}
joao.f.uller@grad.ufsc.br, joao.vicente.souto@grad.ufsc.br, pedro.penna@sga.pucminas.br, marcio. castrodufsc.br, cotalpucminas.br
\end{abstract}

\begin{abstract}
Resumo. Particularidades arquiteturais e o pouco suporte para lightweight manycores fazem com que o porte de aplicações seja árduo nesses processadores. Este trabalho propõe a implementação de um subconjunto do padrão MPI sobre os mecanismos de comunicação de baixo nível existentes no Nanvix, um SO distribuído com foco nessa classe de processadores, visando aumentar sua programabilidade sem perdas significativas de desempenho ou portabilidade.
\end{abstract}

\section{Introdução}

Ao longo dos anos, a eficiência energética tornou-se fundamental para os projetos computacionais. A crescente necessidade de desempenho, em paralelo à exigência de menor consumo, fez com que a exploração de paralelismo entre threads se tornasse a solução mais viável para o uso eficaz do crescente número de transistores por chip [Totoni et al. 2012]. Nesse contexto, arquiteturas multicore interconectadas por uma Network-on-Chip (NoC) têm-se mostrado como um dos principais designs para alta eficiência energética [Huang et al. 2013]. Assim, os lightweight manycores surgem como uma ótima solução que provê altas taxas de paralelismo aliadas a um baixo consumo energético, tendo o Kalray MPPA-256 como um exemplo dessa classe de processadores.

No entanto, questões arquiteturais, como restrição de memória e topologia da NoC, fazem com que a tarefa de portar aplicações para essas arquiteturas seja não trivial. Por isso, faz-se necessária a disponibilização de ambientes de desenvolvimento que equilibrem melhor desempenho, escalabilidade e programabilidade. Este trabalho propõe a implementação de um subconjunto das funções do Message Passing Interface (MPI), visando aproveitar ao máximo as características dessas arquiteturas de maneira simplificada. Alguns trabalhos anteriores propuseram adaptar implementações existentes do MPI para processadores que utilizam NoCs [Totoni et al. 2012]. No entanto, essas soluções não são viáveis para sistemas com memórias restritivas como lightweight manycores [Ho et al. 2015], devido a pilhas de software excessivas. O objetivo é desenvolver uma solução viável para sistemas tão restritivos e que seja portável entre as diferentes arquiteturas, equilibrando desempenho e programabilidade. Isso será possível através do uso do Nanvix ${ }^{1}$, um sistema operacional com foco em lightweight manycores.

\footnotetext{
${ }^{1}$ https://github.com/nanvix/
} 


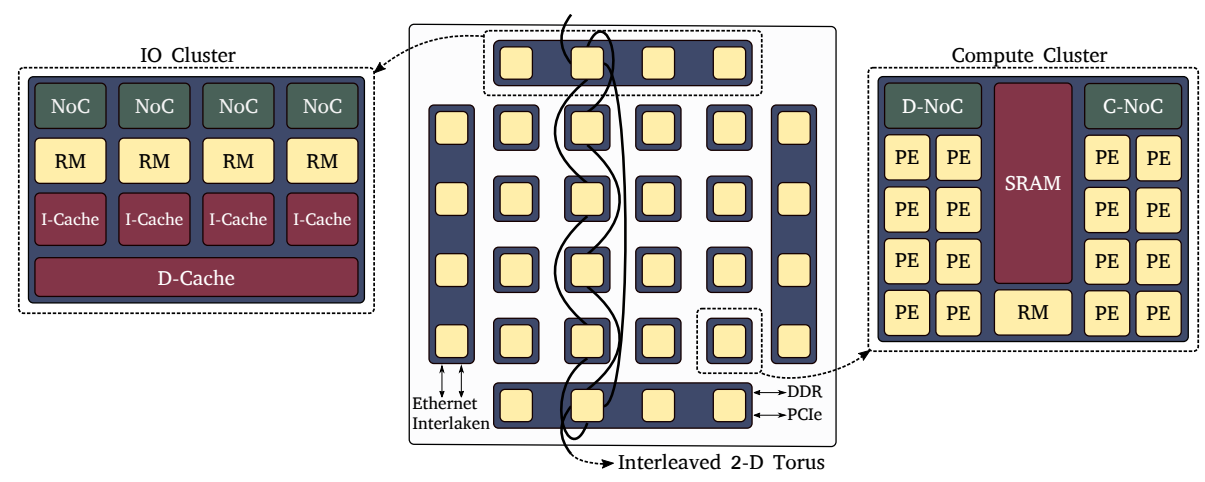

Figura 1. Visão geral simplificada do Kalray MPPA-256 [Penna et al. 2019b].

\section{O Processador Kalray MPPA-256 e o Nanvix}

O Kalray MPPA-256 é uma das arquiteturas suportadas pelo Nanvix e o processador no qual serão executados os experimentos do presente trabalho. Na Figura 1 tem-se uma visão geral do Kalray MPPA-256. Ele integra 16 Clusters de Computação (CCs) com 16 Processing Elements (PEs) e um Resource Manager (RM) cada, além de 4 Clusters de I/O (IOs), com 4 núcleos cada, para comunicação com periféricos, integrando ao todo 288 núcleos no mesmo chip. Cada CC conta com $2 \mathrm{MB}$ de memória compartilhada entre os PEs, e tanto IOs quanto CCs são conectados por duas NoCs, uma para dados (D-NoC) e outra para comandos (C-NoC), para comunicação através de troca de mensagens.

O Nanvix é um Sistema Operacional (SO) de código aberto, compatível com o padrão POSIX, que tem como foco principal atender às necessidades dos lightweight manycores buscando o equilíbrio entre desempenho, portabilidade e programabilidade. Esse sistema utiliza uma estrutura de multikernel, onde cada cluster executa uma instância de um microkernel assimétrico, i.e., um núcleo executa exclusivamente o kernel, deixando os outros núcleos para propósito geral. Essa instância do microkernel é desenvolvida de modo a prover compartilhamento de recursos, serviços mínimos de SO, além de primitivas e abstrações de recursos a nível de cluster [Penna et al. 2019a]. Os diversos clusters comunicam-se através de trocas de mensagens utilizando abstrações de baixo nível fornecidas pelo módulo de comunicação do kernel. As abstrações fornecidas pelo SO que servirão de base para a implementação proposta pelo presente trabalho são: i) syncs para a criação de barreiras de sincronização; ii) mailboxes para troca de mensagens curtas e de tamanho fixo; iii) portals para transferências de dados densas e de tamanho variável.

\section{Proposta de Suporte Parcial ao Padrão MPI no Nanvix}

Apesar dos vários esforços que têm sido empreendidos, o MPI ainda não é um padrão suportado de maneira satisfatória nos lightweight manycores existentes, como o Kalray MPPA-256. A proposta do presente trabalho envolve implementar um subset de funções do padrão MPI, bem como algumas de suas abstrações como grupos e comunicadores, visando não apenas permitir o uso da biblioteca MPI para o porte de aplicações no Nanvix, mas principalmente viabilizar futuras extensões desse suporte e das funcionalidades disponibilizadas. Essa implementação será feita utilizando a infraestrutura de Inter-Process Communication (IPC) do Nanvix e suas abstrações - Sync, Mailbox e Portal [Souto et al. 2019] - que oferecem uma visão uniforme e padronizada, no nível do kernel, dos recursos de comunicação disponíveis nas diferentes arquiteturas suportadas.

Essa implementação coloca-se como uma opção de maior potencialidade ao multikernel provido pelo SO, uma vez que dá maior controle ao programador sobre as 
comunicações e possui uma pilha de software menor, enquanto compensa um esperado overhead em relação ao uso direto das abstrações com uma maior programabilidade. Dentre as funções propostas estão: MPI_Init, MPI_Finalize, MPI_Comm_create, MPI_Comm_size, MPI_Comm_rank, MPI_Comm_group, MPI_Group_free, MPI_Send e MPI_Recv, onde a escolha pelas duas últimas se dá pelo fato do Nanvix suportar, atualmente, apenas o modo síncrono de comunicação.

No entanto, a implementação de um padrão como o MPI em arquiteturas restritivas como os lightweight manycores envolve vários desafios. O principal se refere à limitação de memória disponível em cada cluster, que inviabiliza a adaptação de soluções já existentes como OpenMPI ${ }^{2}$ ou $\mathrm{MPICH}^{3}$, e exige uma implementação desde o princípio que seja mínima. Outro desafio se encontra na necessidade de que o SO base ofereça suporte à virtualização e à multiplexação dos recursos de comunicação. Esse suporte é indispensável, uma vez que se espera estabelecer a ideia de múltiplos comunicadores e canais de comunicação de maneira transparente no nível de usuário, o que não acontece na maioria dos SOs desenvolvidos para essa classe de processadores.

O Nanvix, apesar de suportar virtualização, ainda não suporta a multiplexação dos canais. Assim, o presente trabalho apresenta uma solução de multiplexação para a abstração Portal, aliando a virtualização dos recursos ao endereçamento por portas lógicas, semelhante àquilo que acontece em redes de computadores. A virtualização consiste em armazenar Portals virtuais no kernel e depois mapeá-los para os recursos expostos pela Camada de Abstração de Hardware (HAL). Para a multiplexação, cada Portal virtual é associado a uma porta lógica, criada como um endereço no microkernel que está vinculada ao respectivo recurso de hardware. A partir daí, as trocas de mensagens são feitas endereçando o cluster e a porta lógica de destino, que representa a thread à qual se endereça a mensagem. Esse controle da multiplexação é feito totalmente no nível do kernel, sendo independente de arquitetura, uma vez que não altera a forma como o envio dos dados é feito pela HAL através da NoC. Um header com as informações do endereçamento é anexado no início do buffer que será transferido do lado do emissor, e após isso, o receptor é quem se encarrega de realizar o devido encaminhamento das mensagens recebidas pela NoC para as devidas portas lógicas no kernel.

\section{Resultados Experimentais}

Para avaliar o overhead decorrente da implementação de um modelo MPI, fezse uma avaliação do impacto inicial, resultante de se adicionar a multiplexação dos canais de comunicação, observando a vazão obtida em transferências de dados utilizando Portal. Para isso, foi utilizada a rotina de comunicação Pingpong [Wickramasinghe and Lumsdaine 2016], existente no Nanvix. Foram realizadas 40 iterações para cada cenário obtendo $95 \%$ de confiança com desvio padrão de $10 \%$, obtido em relação à média do pior caso de cada iteração. Cada cenário consistiu em utilizar diferentes números de threads em cada cluster, avaliando a degradação do desempenho à medida que se aumenta a disputa pela utilização do único canal físico multiplexado. No $\mathrm{IO}$, o número de cores utilizado foi fixado em 3 , enquanto no $\mathrm{CC}$ esse número foi sendo aumentado gradativamente. Cada mensagem possuía $1 \mathrm{~KB}$ de dados, onde cada thread do CC enviava e recebia uma mensagem de alguma thread no IO.

A Figura 2 mostra os resultados obtidos. Nela pode-se ver que no caso de apenas uma thread em cada cluster (i.e., sem multiplexação) a vazão obtida foi próxima à obtida em [Souto et al. 2019], como esperado. No entanto, à medida que a disputa pelo canal au-

\footnotetext{
${ }^{2}$ https://www.open-mpi.org/

${ }^{3}$ https://www.mpich.org/
} 


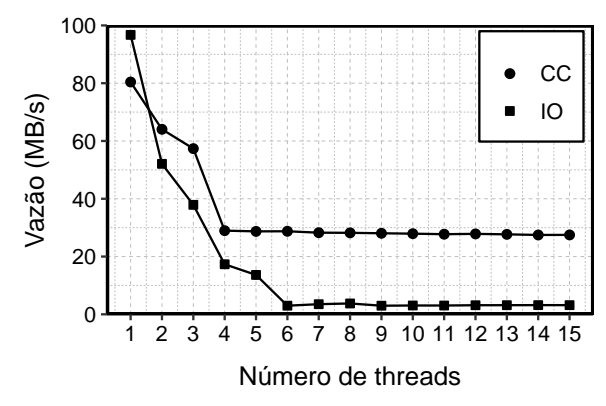

Figura 2. Resultados iniciais de vazão.

menta, a vazão cai consideravelmente, uma vez que perde-se mais tempo reencaminhando as mensagens corretamente no kernel, o que não acontece quando não se tem a necessidade de endereçamento. Pode-se ver também que no CC a vazão é maior e se estabiliza antes, mesmo que com um número maior de threads que o IO. Isso mostra que, mesmo que se tenha uma maior concorrência pelo canal desse lado, seu paralelismo maior, em detrimento à necessidade do $\mathrm{IO}$ de atender às outras portas sequencialmente, faz com que ele tenha um fluxo contínuo de dados e, consequentemente, uma maior vazão.

\section{Conclusão}

Neste trabalho foi feita a proposta de suporte a um subset inicial do MPI sobre a infraestrutura de comunicação de baixo nível do Nanvix. No entanto, como o mesmo ainda não suporta a multiplexação dos recursos, foi realizada uma implementação dessa multiplexação para a abstração Portal. Foi visto que é possível fazer essa multiplexação obtendo resultados satisfatórios, sendo uma possibilidade aumentar o tamanho dos pacotes para um ganho na vazão. Como trabalhos futuros, tem-se a implementação do suporte à multiplexação de Mailboxes e Syncs, antes da implementação do MPI propriamente dita.

\section{Referências}

Ho, M.-Q., Tourancheau, B., Obrecht, C., Dupont De Dinechin, B., and Reybert, J. (2015). MPI communication on MPPA Many-core NoC: design, modeling and performance issues. In ParCo 2015, Edinburgh, United Kingdom.

Huang, L., Wang, Z., Xiao, N., Wang, Y., and Dou, Q. (2013). Adaptive communication mechanism for accelerating mpi functions in noc-based multicore processors. $A C M$ Trans. Archit. Code Optim., 10(3).

Penna, P. H., Souto, J., Lima, D. F., Castro, M., Broquedis, F., Freitas, H. H., and Mehaut, J.-F. (2019a). On the Performance and Isolation of Asymmetric Microkernel Design for Lightweight Manycores. In SBESC, pages 1-8, Natal, Brazil.

Penna, P. H., Souza, M., Jr, E. P., Souto, J., Castro, M., Broquedis, F., de Freitas, H. C., and Méhaut, J.-F. (2019b). RMem: An OS service for transparent remote memory access in lightweight manycores. In MULTIPROG, pages 1-16, Valencia, Spain.

Souto, J. V., Penna, P. H., and Castro, M. (2019). An inter-cluster communication facility for lightweight manycore processors in the nanvix OS. Trabalho de Conclusão, UFSC.

Totoni, E., Behzad, B., Ghike, S., and Torrellas, J. (2012). Comparing the power and performance of intel's scc to state-of-the-art cpus and gpus. 2012 IEEE International Symposium on Performance Analysis of Systems \& Software, pages 78-87.

Wickramasinghe, U. and Lumsdaine, A. (2016). A survey of methods for collective communication optimization and tuning. CoRR, abs/1611.06334. 